\title{
Anti-PD-I Therapy Achieved Disease Control After Multiline Chemotherapy in Unresectable KRAS-Positive Hepatoid Lung Adenocarcinoma: A Case Report and Literature Review
}

This article was published in the following Dove Press journal: OncoTargets and Therapy

\author{
Lulu Chen' \\ Xue $\mathrm{Han}^{2}$ \\ Yujuan Gao $\mathbb{D}^{\prime}$ \\ Qi Zhao' \\ Yongsheng Wang' \\ Ya Jiang ${ }^{2}$ \\ Sisi Liu ${ }^{2}$ \\ Xue $\mathrm{Wu}^{3}$ \\ Liyun Miao' \\ 'Department of Respiratory and Critical \\ Care Medicine, Nanjing Drum Tower, \\ The Affiliated Hospital of Nanjing \\ University Medical School, Nanjing, \\ Jiangsu, People's Republic of China; \\ ${ }^{2}$ Department of Research and \\ Development, Nanjing Geneseeq \\ Technology Inc., Nanjing, Jiangsu, People's \\ Republic of China; ${ }^{3}$ Translational \\ Medicine Research Institute, Geneseeq \\ Technology Inc., Toronto, Ontario, \\ Canada
}

\begin{abstract}
Hepatoid adenocarcinoma of the lung (HAL) is extremely rare and standardized treatment strategy for HAL has not been established. Patients with unresectable HAL have a shorter survival time ranges from 1 to 36 months. Here, we reported a 65 -year-old female patient with unresectable alpha-fetoprotein-producing HAL harboring $K R A S-\mathrm{G} 12 \mathrm{~V}$ and no other targetable driver mutations. The patient was treated with multiple lines of chemotherapies followed by PD-1 inhibitor, sintilimab, due to positive staining of PD-L1, and achieved an overall survival of 52 months. Although the disease was under control, the patient experienced fifth-grade pneumonia and died after 6 months of anti-PD-1 treatment. This is the first case of $K R A S$-positive HAL patient achieved stable disease by PD-1 inhibitor, which may provide valuable information for the treatment strategy development of advanced HAL patients, and highlights the importance of molecular diagnosis in treatment decision-making. Keywords: alpha-fetoprotein, anti-PD-1 therapy, hepatoid adenocarcinoma of the lung, KRAS-G12V, sintilimab
\end{abstract}

\section{Introduction}

Hepatoid adenocarcinoma (HAC) is a rare extrahepatic tumor with morphological and functional features similar to hepatocellular carcinoma. ${ }^{1} \mathrm{HAC}$ of the lung (HAL) accounts for only 5\% of all reported cases of HAC. Two criteria for diagnosis of HAL are usually adopted: (a) tumor composition can be pure hepatoid adenocarcinoma or the tumor with components of typical acinar or papillary adenocarcinoma, neuroendocrine carcinoma or signet-ring cells; (b) markers of hepatic differentiation are expressed, such as monoclonal CEA and EpCAM. ${ }^{2,3}$ The standard treatment strategy of HAL has not been established owing to the rareness of this disease and ineffectiveness of conventional lung cancer regimens, such as radical surgery and chemotherapy. More effective treatment strategies still need to be explored. ${ }^{4}$ Immune checkpoint inhibitors (ICIs) targeting cytotoxic T lymphocyte antigen 4 (CTLA-4) or the programmed cell death 1 (PD-1) pathway to overcome immune suppression in cancer growth and progression have made remarkable success in cancer therapy. Here we present an AFP-producing HAL patient who maintained a partial response to anti-PD-1 immunotherapy after progressed on multiline chemotherapy regimens and eventually achieved an overall survival of 52 months. 


\section{Case Presentation}

A 65-year-old female with no smoking or alcohol consumption history was initially diagnosed with stage IV bilateral lung adenocarcinoma in February 2015 (Figure 1). Bone metastasis was observed with bone emission computed tomography (ECT) scan. Immunohistochemistry (IHC) staining of tumor biopsy showed positive for SALL4, AFP, GPC3, CK7 and Villin. In contrast, TTF, napsin A and Hept1 were negative (Figure 2). Meanwhile, the serum AFP level was as high as $6818 \mathrm{ng} / \mathrm{mL}$, and computed tomography (CT) scan and B-ultrasound of the liver ruled out a primary hepatocellular carcinoma. Collectively, the patient was confirmed with a stage IV AFP-producing HAL.

As the tumor was surgically unresectable, IHC staining for ALK was negative, and no EGFR mutation was identified with qPCR, the patient was given chemotherapy consisting of docetaxel $(40 \mathrm{mg})$ and oxaliplatin $(100 \mathrm{mg})$ every 4 weeks for 5 cycles. During this period of treatment, the patient achieved a stable disease (SD) until April 2016. However, due to liver function damage, the patient received combination therapy with pemetrexed (800 mg) and oxaliplatin (200 mg) plus bevacizumab (400 mg), a recombinant humanized monoclonal antibody directed against the vascular endothelial growth factor (VEGF). After 2 cycles of treatment in July 2016, a chestCT demonstrated that the size of both pulmonary lesions increased, which indicated progressive disease (PD).
Therefore, the patient was re-treated with docetaxel and oxaliplatin (DO) plus bevacizumab and maintained at an $\mathrm{SD}$ of 22 months. However, the diseased progressed in July 2018 with an increased AFP level $(>10,000 \mathrm{ng} / \mathrm{mL})$ and an enlargement of the pulmonary lesions revealed by chest-CT. Then, the patient was given one cycle of gemcitabine and nedaplatin therapy but showed obvious side effects such as nasal septum bleeding and decreased platelet count. Three months later, a newly acquired metastatic site and enlarged primary lesions were observed in both lungs, indicating a PD. Anlotinib is a novel oral multitarget tyrosine kinase inhibitor and has been approved for the treatment of advanced non-small-cell lung cancer (NSCLC). Then, the patient took anlotinib at the dose of $12 \mathrm{mg}$ per day for 2 weeks since September 2018. Although achieved a stable disease (SD), the patient had to stop the anlotinib treatment due to severe side effects of third-grade hand-foot syndrome. Therefore, the chest-CT showed PD again in December 2018. To this end, the patient refused to take other chemotherapy regiments, and the Eastern Cancer Cooperative Group (ECOG) performance status score was 4 .

In order to find a more efficient therapeutic strategy, targeted NGS of 425 cancer-related genes was applied to the plasma circulating tumor DNA (ctDNA) and tumor samples (Table 1). A KRAS hotspot G12V (c. 35G>T) mutation was revealed at a mutant allele frequency (MAF) of $19.5 \%$ in
Anti-PD-1 therapy

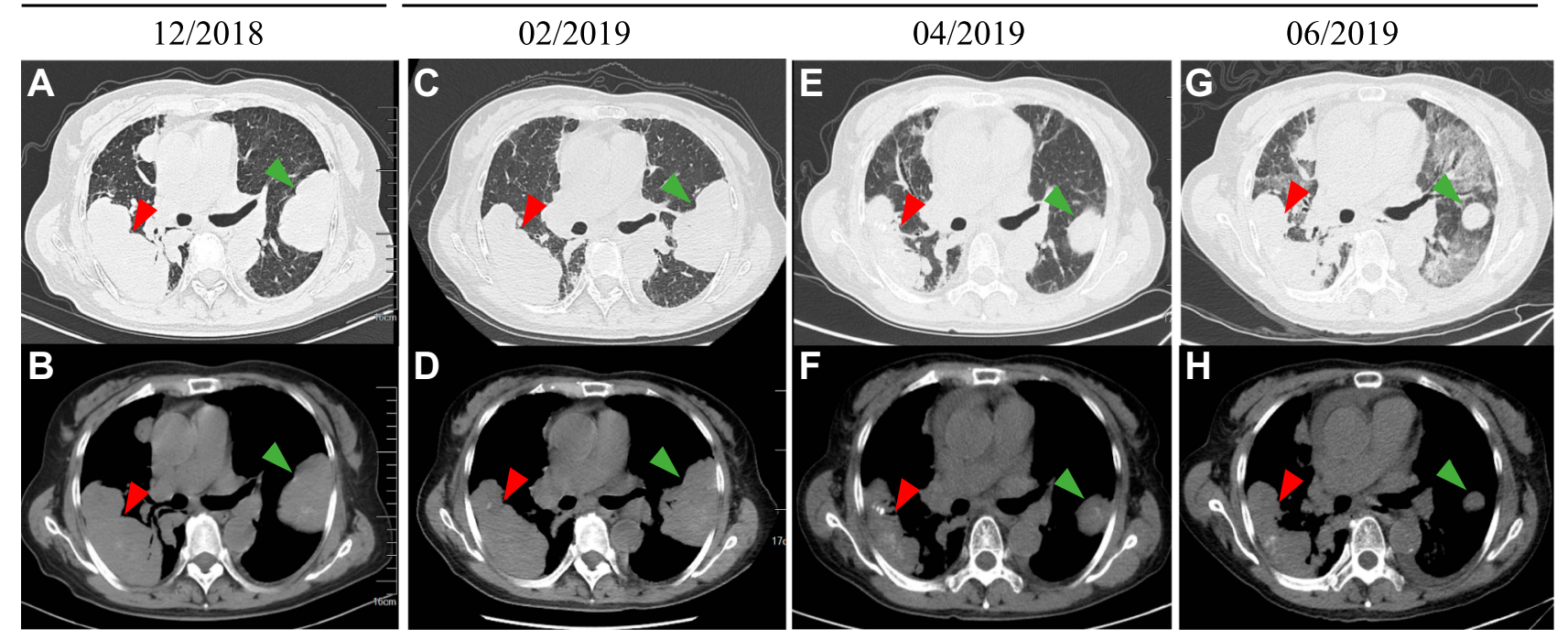

Figure I Chest-CT scans showed tumor mass at different stages of the disease including before anti-PD-I therapy and anti-PD-I therapy. (A) Lung window and (B) mediastinal window views of CT scan showed a PD after multiline chemotherapy with an increase in the size of the left lung $(7 \times 5.1 \mathrm{~cm}$, green arrow) and right lung $(9.2 \times 4.6 \mathrm{~cm}$, red arrow). During anti-PD-I therapy, (C, D) showed the patient received an SD with the size of the left lung $(7.7 \times 5.1 \mathrm{~cm}$, green arrow) and right lung $(9.6 \times 4.6 \mathrm{~cm}$, red arrow) in February 2019. (E, F) showed the patient achieved a PR with a decrease in the size of the left lung $(5.6 \times 3.8 \mathrm{~cm}$, green arrow) and right lung $(8.4 \times 3.2 \mathrm{~cm}$, red arrow) in April 2019 and $(\mathbf{G}, \mathbf{H})$ showed the size of the left lung $(5.1 \times 3.3 \mathrm{~cm}$, green arrow) and right lung $(8.7 \times 3.4 \mathrm{~cm}$, red arrow) in June 2019 . 

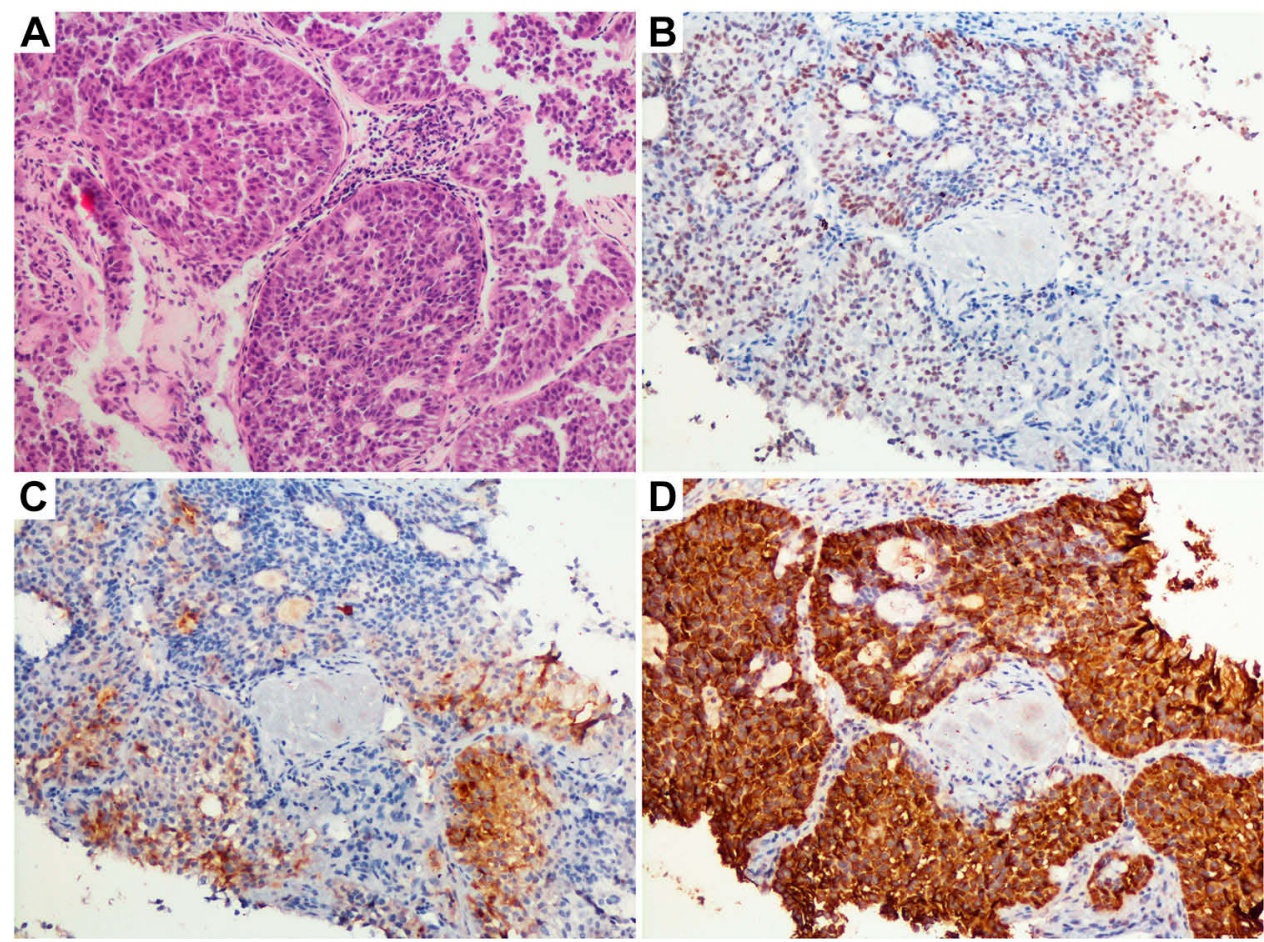

Figure 2 Pathologic analysis of primary tumor biopsy, indicating hepatoid adenocarcinoma of the lung. (A) The hematoxylin and eosin stain of the lung masses showed morphologic features similar to hepatocytes with large, nucleated and centrally located nuclei (200x). (B-D) Immunohistochemical stains showed tumor cells to be positive for SALL4, AFP and GPC3 (200x)

plasma and $74.7 \%$ in tumor tissue. Although $K R A S \mathrm{G} 12 \mathrm{~V}$ is a known driver mutation in multiple cancer types, the major obstacle remains the lack of effective targeted drugs. The patient did not harbor high tumor mutation burden $(8 \mathrm{mut} / \mathrm{M})$ and was microsatellite stable (MSS). Furthermore, considering that the tumor showed a positive IHC staining of programmed death ligand 1 (PD-L1) expression ( $\geq 1 \%$ ), we recommended PD-L1 inhibitor immunotherapy in this patient. ${ }^{5}$ Sintilimab, a novel anti-PD-1 monoclonal antibody which showed efficacy with an acceptable safety profile in NSCLC was used. The patient was subjected to the treatment of docetaxel $(80 \mathrm{mg})$ plus sintilimab $(200 \mathrm{mg})$ in January 2019, then, the chest-CT showed an SD

Table I Genetic Alterations Detected in the Plasma and Tumor Biopsies

\begin{tabular}{|l|l|l|l|l|}
\hline Gene & Variation & $\begin{array}{l}\text { Nucleotide } \\
\text { Change }\end{array}$ & Plasma & Tissue \\
\hline KRAS & P. GI2V & c. $35 \mathrm{G}>\mathrm{T}$ & $19.5 \%$ & $74.7 \%$ \\
ARIDIA & P. R750X & c. $2248 \mathrm{C}>\mathrm{T}$ & $3.7 \%$ & - \\
MDM4 & Gene amplification & NA & - & 1.7 -fold \\
\hline
\end{tabular}

Notes: Mutations were shown as mutant allele frequency. Gene amplification was shown as a relative fold change to a normal control sample.

Abbreviations: NA, not applicable; -, not detectable.
(Figure 1B). Immunotherapy was well responded by the patient except that her complete blood count showed a second-grade myelosuppression, then the combination of docetaxel was discontinued. Therefore, the patient was continually received 3 times of sintilimab therapy every 4 weeks since February 2019. Lesions in right and left lung showed significant partial response (PR) (Figure 1C). Unfortunately, the patient succumbed to fifth-grade interstitial pneumonia and died in July 2019 with a total survival benefit of 6 months from anti-PD-1 therapy.

\section{Discussion}

HAC is an extremely rare tumor type that was first described as gastric tumor. ${ }^{6}$ Subsequent studies reported that the most common HAC sites were stomach (63\%), and less commonly in ovary (10\%), lung (5\%), gallbladder (4\%), pancreas $(4 \%)$ and uterus (4\%). Extremely high level of serum AFP is observed in nearly $80 \%$ cases. In this case, the patient was diagnosed with HAL according to morphologic and immunohistochemical features, accompanied by a high serum AFP level. ${ }^{7,8}$ According to previous studies, most cases of HAL are negative for known driver mutations, only two cases were reported to have $A L K$ rearrangement and $E G F R$ mutation, respectively. We reported the patient harbored a $K R A S \mathrm{G} 12 \mathrm{~V}$ 
Table 2 All Reported Literature Cases of HAL Treated with Chemotherapy

\begin{tabular}{|c|c|c|c|c|c|c|c|}
\hline $\begin{array}{l}\text { Autor, Publication } \\
\text { Year }\end{array}$ & $\begin{array}{l}\text { Age } \\
\text { (Years) }\end{array}$ & Gender & Smoker & $\begin{array}{l}\text { AFP Level (ng/ } \\
\mu \mathrm{L})\end{array}$ & Stage & Survival & Treatment \\
\hline $\begin{array}{l}\text { Arnould et al, } \\
1997^{11}\end{array}$ & 36 & Male & Yes & 11,600 & IIIB & Died, 17 months & Chemotherapy, surgery \\
\hline Nasu et al, $1997^{12}$ & 63 & Male & NA & 14,000 & IIIB & Alive, II months & Chemotherapy \\
\hline $\begin{array}{l}\text { Hiroshima et al, } \\
2002^{13}\end{array}$ & 70 & Male & Yes & 24.3 & IIIB & Alive, 24 months & Chemotherapy, surgery \\
\hline Ivan et al, $2007^{14}$ & 54 & Male & Yes & 14,540 & IVB & Not reported & Chemotherapy, radiotherapy \\
\hline $\begin{array}{l}\text { Papatsimpas et al, } \\
2012^{15}\end{array}$ & 48 & Male & Yes & 39,000 & IIIA & Not reported & Chemotherapy, radiotherapy \\
\hline Mokrim et al, $2012^{16}$ & 52 & Male & Yes & 5000 & IVA & Alive, 6 months & Chemotherapy \\
\hline $\begin{array}{l}\text { Valentino et al, } \\
2012^{17}\end{array}$ & 71 & Male & No & 34,791 & IVA & Died, 4 months & $\begin{array}{l}\text { Surgery, chemotherapy, } \\
\text { radiotherapy }\end{array}$ \\
\hline $\begin{array}{l}\text { Lin et al, } 2013^{18} \\
\text { Haninger et al, } 2014^{1}\end{array}$ & 66 & Male & Yes & 8686 & IIIB & Alive, 57 months & $\begin{array}{l}\text { Surgery, adjuvant } \\
\text { chemotherapy }\end{array}$ \\
\hline Case I & 51 & Male & Yes & $\begin{array}{l}\text { I.3 (post- } \\
\text { treatment) }\end{array}$ & IVA & Died, 14 months & $\begin{array}{l}\text { Surgery, chemotherapy, } \\
\text { radiotherapy }\end{array}$ \\
\hline Case 2 & 52 & Male & Yes & Not assayed & IVA & Alive, 37 months & $\begin{array}{l}\text { Surgery, chemotherapy, } \\
\text { radiotherapy }\end{array}$ \\
\hline Case 3 & 64 & Male & Yes & I (post-treatment) & IVA & Died, 10 months & $\begin{array}{l}\text { Surgery, chemotherapy, } \\
\text { radiotherapy }\end{array}$ \\
\hline Case 4 & 54 & Female & Yes & NA & IVA & Alive, 108 months & $\begin{array}{l}\text { Surgery, chemotherapy, } \\
\text { radiotherapy }\end{array}$ \\
\hline Case 5 & 60 & Male & Yes & 4410 & IVA & Alive, I month & Chemotherapy, radiotherapy \\
\hline Shaib et al, $2014^{19}$ & 52 & Male & Yes & 5000 & IVA & Alive, 6-7 months & Chemotherapy \\
\hline Che et al, $2014^{20}$ & 48 & Male & Yes & 6283 & IIIA & Died, 36 months & Chemotherapy, radiotherapy \\
\hline $\begin{array}{l}\text { Gavrancic et al, } \\
2015^{3}\end{array}$ & 64 & Male & NA & 181 & IVA & Died, II months & $\begin{array}{l}\text { Chemotherapy, sorafenib, } \\
\text { radiotherapy }\end{array}$ \\
\hline Qian et al, $2016^{21}$ & 79 & Male & Yes & 698 & NA & Died, I month & Chemotherapy \\
\hline Shao et al, $2016^{22}$ & 42 & Male & Yes & NA & IIIB & Died, 3 months & Chemotherapy, surgery \\
\hline Valle et al, $2017^{23}$ & 61 & Male & NA & NA & IVA & Died, 10 months & Chemotherapy \\
\hline Basse et al, $2018^{2}$ & 43 & Male & Yes & NA & IVB & Died, not reported & $\begin{array}{l}\text { Chemotherapy, } \\
\text { immunotherapy }\end{array}$ \\
\hline $\begin{array}{l}\text { El Khoury et al, } \\
2019^{24}\end{array}$ & 59 & Male & Yes & 1.5 & IVA & Alive, 10 months & $\begin{array}{l}\text { Chemotherapy, } \\
\text { immunotherapy }\end{array}$ \\
\hline & 65 & Female & No & 6818 & IVA & Died, 52 months & $\begin{array}{l}\text { Chemotherapy, } \\
\text { immunotherapy }\end{array}$ \\
\hline
\end{tabular}

Abbreviation: NA, not applicable.

mutation and was negative for other driver mutations. To our knowledge, this is the first report of HAL harboring a KRAS mutation. ${ }^{9}$ In NSCLC, many novel covalent inhibitors targeting $K R A S$ are currently under investigation for clinical trials. However, ${ }^{10}$ effective therapies against $K R A S$ have not been developed yet, and the major obstacle remains the lack of effective targeted drugs.

Neoadjuvant chemotherapy plus surgical resection could be used to treat non-advanced HAL, whereas the regimens for advanced-stage patients have not been established. ${ }^{1-3,11-24}$ We searched all known cases of
HAL and included a total of 22 patients who were treated with chemotherapy and immunotherapy in the literature review (Table 2). Interestingly, most of the patients were male (20/22) and only 2 female cases (including the present case) were reported which indicated a sex difference of HAL. Survival for resectable HAL patients ranged from 3 to 108 months among which $44.4 \%$ (4/9) longer than 24 months. However, for unresectable HAL, survival ranges from 1 to 36 months, and only one case (1/9) achieved a survival longer than 24 months. In the case we reported here, the patient had an unresectable HAL but achieved an 
overall survival of 52 months from multiple lines of treatment including chemotherapy and anti-PD1 therapy. ${ }^{25}$

ICIs targeting PD-(L)1 represent a standard treatment option for patients with advanced NSCLC and have shown promising response in clinical treatment. ${ }^{26}$ Positive PD-L1 expression, high tumor mutation burden and mismatch repair-deficient have been proposed as a potential predictor for response to $\mathrm{ICI}^{27}$ Furthermore, KRAS and ARIDIA mutations which may increase ICI treatment efficiency were also observed. These results indicated that the patient may benefit from anti-PD-(L)1 immunotherapy. ${ }^{28}$ It was reported that $M D M 2 / M D M 4$ gene amplification ( $>8$-fold) was correlated with hyper-progressive disease (HPD) after single-agent checkpoint (PD-(L)1) inhibitors, but the patient we reported did not experience HPD. One reason for this phenomenon was the moderate amplification ratio score of MDM4 (1.7-fold) which could not affect cell function significantly. Furthermore, anti-PD-(L)1 immunotherapy after chemotherapy may have an impact on the immune microenvironment of tumors and decrease HPD. ${ }^{29}$

It has been reported that poor ECOG performance status score was associated with HPD and poor prognosis in patients with NSCLC undergoing PD-1/PD-L1 blockade treatment. Pneumonitis (1.4\%) was reported to be the most common immune-related adverse events (irAE), although the mechanism underlying irAE is not well understood, the risk of organ-specific irAE has been reported in anti-PD -(L)1 immunotherapy. ${ }^{30}$ The unfavorable irAE may be caused by a combination of various factors, including poor physical condition and tumor progression following multiline chemotherapy in the patient we reported. For advanced and unresectable HAL patients, considering the precondition of effective treatment and reducing side effects of chemotherapy will achieve more response to patients. In this case, the patient still showed partial response with anti-PD-1 immunotherapy before additional side effects. We would like to emphasize that ICIs treatment may be a potential treatment for KRAS mutation HAL patients, but attention should be paid to patients with poor ECOG performance status to avoid severe irAE. Still, further detailed studies are needed to validate the clinical activity and safety of PD-(L)1 blockade treatment in these patients.

\section{Conclusion}

In summary, our report first presented an unresectable AFP-producing and $K R A S$-positive HAL patient treated with multiline chemotherapy followed by anti-PD-1 immunotherapy who achieved an overall survival of 52 months. This finding would provide valuable information for treatment decision-making and irAE prevention of similar advanced HAL patients.

\section{Data Sharing Statement}

All datasets generated for this study are included in the manuscript.

\section{Ethics Statement}

The studies involving human participants were reviewed and approved by Ethics Committee of Nanjing Drum Tower Hospital. The patients/participants provided their written informed consent to participate in this study. Written informed consent was obtained from the patient's family member for publication of this case report and any accompanying images. We would like to thank the patient and his family for giving consent for publication. We also thank all staffs involved in this case study.

\section{Acknowledgment}

This study was supported by the grants from the Key Project of Nanjing Public Health Bureau (No. ZKX15020) and Wu Jieping Medical Foundation (320.6750.17242 and 320. 6750.19081).

\section{Author Contributions}

All authors made substantial contributions to conception and design, acquisition of data, or analysis and interpretation of data; took part in drafting the article or revising it critically for important intellectual content; gave final approval of the version to be published; and agree to be accountable for all aspects of the work.

\section{Disclosure}

$\mathrm{XH}, \mathrm{YJ}$ and SL are the employees of Nanjing Geneseeq Technology Inc., China; XW is the employee of Geneseeq Technology Inc., Canada. The authors report no other conflicts of interest in this work.

\section{References}

1. Haninger DM, Kloecker GH, Bousamra II M, Nowacki MR, Slone SP. Hepatoid adenocarcinoma of the lung: report of five cases and review of the literature. Mod Pathol. 2014;27(4):535-542. doi:10.1038/ modpathol.2013.170

2. Basse V, Schick U, Guéguen $P$, et al. A mismatch repair-deficient hepatoid adenocarcinoma of the lung responding to anti-PD-L1 durvalumab therapy despite no PD-L1 expression. J Thorac Oncol. 2018;13 (7):e120-e2. doi:10.1016/j.jtho.2018.03.004 
3. Gavrancic T, Park YH. A novel approach using sorafenib in alpha fetoprotein-producing hepatoid adenocarcinoma of the lung. $J$ Natl Compr Canc Netw. 2015;13(4):387-391. doi:10.6004/jnccn.2015.0054

4. Topalian SL, Drake CG, Pardoll DM. Immune checkpoint blockade: a common denominator approach to cancer therapy. Cancer Cell. 2015;27(4):450-461. doi:10.1016/j.ccell.2015.03.001

5. Nong X, Kejing Y, Ziping W, et al. Phase Ib study of sintilimab in combination with chemotherapy for $1 \mathrm{~L}$ advanced or metastatic non-small cell lung cancer (NSCLC). J Clin Oncol. 2019;37 (15_suppl):e20546-e. doi:10.1200/JCO.2019.37.15_suppl.e220546

6. Xiao C, Wu F, Jiang $\mathrm{H}$, et al. Hepatoid adenocarcinoma of the stomach: nine case reports and treatment outcomes. Oncol Lett. 2015;10(3):1605-1609. doi:10.3892/ol.2015.3430

7. Nishino M, Klepeis VE, Yeap BY, et al. Histologic and cytomorphologic features of ALK-rearranged lung adenocarcinomas. Mod Pathol. 2012;25(11):1462-1472. doi:10.1038/modpathol.2012.109

8. Chen HF, Wang WX, Li XL, et al. Hepatoid adenocarcinoma of the lung with EGFR mutation and the response to tyrosine kinase inhibitors. J Thorac Oncol. 2019;14(10):e217-e9. doi:10.1016/j.jtho. 2019.04.032

9. Ryan MB, Corcoran RB. Therapeutic strategies to target RAS-mutant cancers. Nat Rev Clin Oncol. 2018;15(11):709-720. doi:10.1038/ s41571-018-0105-0

10. Tomasini P, Walia P, Labbe C, Jao K, Leighl NB. Targeting the KRAS pathway in non-small cell lung cancer. Oncologist. 2016;21 (12):1450-1460. doi:10.1634/theoncologist.2015-0084

11. Arnould L, Drouot F, Fargeot P, et al. Hepatoid adenocarcinoma of the lung: report of a case of an unusual alpha-fetoprotein-producing lung tumor. Am J Surg Pathol. 1997;21(9):1113-1118. doi:10.1097/ 00000478-199709000-00018

12. Nasu M, Soma T, Fukushima H, Kudo K, Matsubara O. Hepatoid carcinoma of the lung with production of alpha-fetoprotein and abnormal prothrombin: an autopsy case report. Mod Pathol. 1997;10(10):1054-1058.

13. Hiroshima K, Iyoda A, Toyozaki T, et al. Alpha-fetoproteinproducing lung carcinoma: report of three cases. Pathol Int. 2002;52(1):46-53. doi:10.1046/j.1440-1827.2002.01311.x

14. Ivan M, Koss M, Chang CF. Hepatoid adenocarcinoma of the lung. Chest. 2007;132(4):690A. doi:10.1378/chest.132.4_MeetingAbstracts.690

15. Papatsimpas G, Kamposioras K, Goula K, et al. Hepatoid pancoast tumor. A case report and review of the literature. Lung Cancer. 2012;77(2):239-245. doi:10.1016/j.lungcan.2012.05.102

16. Mokrim M, Belbaraka R, Allaoui M, et al. Hepatoid adenocarcinoma of the lung: a case report and literature review. J Gastrointest Cancer. 2012;43(S1):125-127. doi:10.1007/s12029-011-9318-5

17. Valentino F, Torchio M, Morbini P, Danova M. Synchronous presentation of hepatoid alpha-fetoprotein-producing lung cancer and colorectal adenocarcinoma. Tumori. 2012;98(5):130e-4e. doi:10.1700/1190.13214
18. Lin SF, Hsu WH, Chou TY. Primary pulmonary hepatoid carcinoma: report of a case and review of the literature. Kaohsiung J Med Sci. 2013;29(9):512-516. doi:10.1016/j.kjms.2013.01.007

19. Shaib W, Sharma R, Mosunjac M, Farris AB, El Rayes B. Hepatoid adenocarcinoma of the lung: a case report and review of the literature. J Gastrointest Cancer. 2014;45(S1):99-102. doi:10.1007/ s12029-013-9558-7

20. Che YQ, Wang S, Luo Y, Wang JB, Wang LH. Hepatoid adenocarcinoma of the lung: presenting mediastinal metastasis without transfer to the liver. Oncol Lett. 2014;8(1):105-110. doi:10.3892/ol.2014. 2064

21. Qian GQ, Yin FY, Li GX, et al. Hepatoid adenocarcinoma of the lung. $Q J M$. 2016;109(9):619-620. doi:10.1093/qjmed/hcw107

22. Shao Y, Zhong DS, Wang D, et al. Hepatoid adenocarcinoma of the lung: a case report. Int J Clin Exp Pathol. 2016;9:4067-4072.

23. Valle L, Thomas J, Kim C, et al. Hepatoid adenocarcinoma of the lung metastasizing to the tonsil. Mol Clin Oncol. 2017;6(5):705-707. doi:10.3892/mco.2017.1215

24. El Khoury A, El Khoury M, De Luca R. Immunotherapeutic approach to a case of advanced hepatoid adenocarcinoma of the lung. Mag Eur Med Oncol. 2019;12(3):272-277. doi:10.1007/ s12254-019-0499-0

25. Califano R, Lal R, Lewanski C, et al. Patient selection for anti-PD-1/ PD-L1 therapy in advanced non-small-cell lung cancer: implications for clinical practice. Future Oncol. 2018;14(23):2415-2431. doi:10.2217/fon-2018-0330

26. Shukuya T, Carbone DP. Predictive markers for the efficacy of anti-PD-1/PD-L1 antibodies in lung cancer. $J$ Thorac Oncol. 2016;11(7):976-988. doi:10.1016/j.jtho.2016.02.015

27. Jeanson A, Tomasini P, Souquet-Bressand M, et al. Efficacy of immune checkpoint inhibitors in KRAS-mutant non-small cell lung cancer (NSCLC). J Thorac Oncol. 2019;14(6):1095-1101. doi:10.10 16/j.jtho.2019.01.011

28. Champiat S, Dercle L, Ammari S, et al. Hyperprogressive disease is a new pattern of progression in cancer patients treated by anti-PD-1/ PD-L1. Clin Cancer Res. 2017;23(8):1920-1928. doi:10.1158/10780432.Ccr-16-1741

29. Grangeon M, Tomasini P, SJeanson AC, et al. Association between immune-related adverse events and efficacy of immune checkpoint inhibitors in non-small-cell lung cancer. Clin Lung Cancer. 2019;20 (3):201-207. doi:10.1016/j.cllc.2018.10.002

30. Baxi S, Yang A, Gennarelli RL, et al. Immune-related adverse events for anti-PD-1 and anti-PD-L1 drugs: systematic review and meta-analysis. BMJ. 2018;360:k793. doi:10.1136/bmj.k793

\section{Publish your work in this journal}

OncoTargets and Therapy is an international, peer-reviewed, open access journal focusing on the pathological basis of all cancers, potential targets for therapy and treatment protocols employed to improve the management of cancer patients. The journal also focuses on the impact of management programs and new therapeutic agents and protocols on patient perspectives such as quality of life, adherence and satisfaction. The manuscript management system is completely online and includes a very quick and fair peer-review system, which is all easy to use. Visit http://www.dovepress.com/ testimonials.php to read real quotes from published authors. 